DOI: 10.12731/2070-7568-2020-4-103-118

УДК 338.23/369.04

\title{
КОМПЛЕКСНЫЙ АНАЛИЗ ФИНАНСОВЫХ ПОТОКОВ В РЕГИОНАЛЬНОМ ЛЕЧЕБНОМ УЧРЕЖДЕНИИ ЗДРАВООХРАНЕНИЯ РЕСПУБЛИКИ ТАТАРСТАН
}

\author{
Зинурова Г.Х., Сафаргалиев Э.Р.
}

Рассматривается актуальная проблема оптимизации управления финансовыми средствами в государственных бюджетных учреждениях здравоохранения. В рамках проводимой государственной политики необходимо четко определить предел социальных гарантий, предоставляемых за счет средств бюджетов, а также создать новые механизмы социальной защитты граждан. Реализация этой задачи во многом зависит от состояния и устойчивости государственных и муниципальных финансов, которые являются основным источником финансирования.

Субъекты Федерации и муниципальные образования самостоятельны в определении перечня целевых программ из-за разных приоритетов социально-экономического развития, различий в структуре органов государственной власти и органов местного самоуправления. При формировании порядка разработки, реализациии и оченки эффективности целевых программ субъекты Федераџии и муниципальные образования должны найти баланс между подходами федерального уровня власти, спецификой территории и особенностяли сущуествующей системы государственного (муниципального) управления ее социально-экономическим развитием.

Органы власти различных уровней вынуждены ограничивать рост бюджетных расходов на фоне неблагоприятной экономической конъюнктуры. Важнейшим условием развития бюджетной системы Российской Федерации в такой ситуации является повышение эффективности использования бюджетных средств. Расходы на здравоохранение занимают около четверти расходов тер- 
риториальных бюджетов. Поэтому одним из важнейших вопросов финансирования государственных медицинских бюджетных учреждений является финансирование за счет средств, получаемых от предоставления платных услуг через активное сотрудничество со страховыми компаниями.

Проведен анализ структуры финансовых потоков, выявлены тенденции и отклонения от плановых значений. Проанализирован эффект сотрудничества лечебного учреждения со страховыми компаниями. В основе сотрудничества заложено варьирование двумя основными переменными факторами - скидкой и ожидаемым приростом спроса на услуги, что позволяет определять эффективность реализации проектов, как по отдельным группам услуг, так и по всей коммерческой деятельности больницы в целом.

Цель - провести сравнительный комплексный анализ финансовых потоков в регчональном лечебном учреждении здравоохранения PT, выделить проблемные аспекты и описать направления повышения доходности медицинского учреждения.

Методы проведения работы: при подготовке настоящей работы использовалось теоретическое изучение методик оценки доходов и расходов лечебно-профилактических учреждений, научно-исследовательской литературы. Исследование основано на применении комплексного анализа доходов и расходов субъектов здравоохранения с использованием данных официальной статистики и финансовой отчетности.

Результаты: проблема оптимизации финансовых потоков стоит перед менеджментом любой практически любой компании. В этом контексте для муниципальных субъектов здравоохранения весьма актуальной является увеличение доходов от оказания платных услуг с учетом спроса на данные услуги и их доступности по ценообразованию.

Область применения результатов: полученные результаты определят эффективность реализации проектов, как по отдельньмм группам услуг, так и по всей коммерческой деятельности больнищьы в целлом. 
Ключевые слова: сметы доходов и расходов; здравоохранение; управление финансами; финансирование.

\title{
INTEGRATED CASH FLOW ANALYSIS OF A REGIONAL MEDICAL TREATMENT FACILITY IN THE REPUBLIC OF TATARSTAN
}

\author{
Zinurova G.Kh., Safargaliev E.R.
}

The current problem of financial management optimization in Publicly Funded Health Facilities is examined. In line with the state policy, it is essential to clearly define the limits of social safety net funded by state budgets and to develop new social protection mechanisms. The implementation of the above largely depends on the status and stability of the state and municipal finances, which are the primary source of funding.

Subordinate entities of the Federation and municipal districts are independent in defining the list of special-purpose programmes due to difference in priorities in social and economic development and in the structure of State and local government bodies. When planning, implementing and assessing the effectiveness of special-purpose programmes, subordinate entities of the Federation and municipal districts must find the balance between the approach of the federal government, area specifics and the specifics of the existing state (municipal) system of managing its social and economic development.

Government bodies of different levels have to reduce their expenditure due to adverse economic situation. In this situation, the most important condition for the development of the Russian budget system is improving the use of public funds. Regional authorities spend about a quarter of their budgets on healthcare. Hence one of the most important funding issues of state healthcare facilities is raising funds by providing commercial services and through active cooperation with insurance companies.

The cashflow structure has been analysed; planned values and deviations have been identified. The effectiveness of cooperation between 
a healthcare facility and insurance companies has been analysed. The cooperation is based on two essential variables: discount and the expected growth of demand for services, which makes it possible to define the effectiveness of projects, both in separate services and overall business activities of a hospital.

The Aim is to perform an integrated cashflow analysis of a regional healthcare facility in the Republic of Tatarstan, to highlight its biggest flaws and problems and to define the ways to increase the income of a healthcare facility.

Method: methods of evaluating income and expenditure in healthcare facilities as well as academic literature have been studied in preparation of this paper. The research is based on the integrated analysis of income and expenditure of healthcare facilities using the official statistics and financial statements data.

Outcomes: the managers of nearly all companies face the problem of cashflow optimization. In this context, increasing the earnings from commercial services subject to demand and affordability is a current issue of municipal healthcare facilities.

Scope: the achieved outcomes shall define how effective the projects are, both in separate services and overall business activities of a hospital

Keywords: income and expenditure estimate; healthcare; financial management; funding.

В условиях кризиса в нашей стране обостряются социально-экономические проблемы. В рамках проводимой государственной политики необходимо четко определить предел социальных гарантий, предоставляемых за счет средств бюджетов, а также создать новые механизмы социальной защиты граждан. Целью исследования является комплексный анализ финансовых потоков в региональном лечебном учреждении здравоохранения Республики Татарстан. Реализация этой задачи во многом зависит от состояния и устойчивости государственных и муниципальных финансов, которые являются основным источником финансирования задач и функций государства $[13$, с. 85$]$. 
Субъекты Федерации и муниципальные образования самостоятельны в определении перечня целевых программ из-за разных приоритетов социально-экономического развития, различий в структуре органов государственной власти и органов местного самоуправления. При формировании порядка разработки, реализации и оценки эффективности целевых программ субъекты Федерации и муниципальные образования должны найти баланс между подходами федерального уровня власти, спецификой территории и особенностями существующей системы государственного (муниципального) управления ее социально-экономическим развитием [4, с. 400].

ГАУЗ «Городская поликлиника №3» г. Набережные Челны является государственным автономным учреждением здравоохранения Приволжского федерального округа, учредителем которого является Министерство здравоохранения Республики Татарстан.

Анализ управления финансами ГАУЗ «Городская поликлиника №3» проведем в следующей последовательности:

1. Сравнительный анализ результатов деятельности ЛПУ за 2017-2019 гг. (табл. 1) по источникам поступления финансовых средств и понесенным затратам.

Таблиияа 1.

Динамика доходов и расходов

ГАУЗ «Городская поликлиника №3» за 2017-2019 гг.

\begin{tabular}{|c|c|c|c|c|c|c|c|}
\hline \multirow[b]{2}{*}{$\begin{array}{c}\text { Статьи доходов } \\
\text { и расходов }\end{array}$} & 2017 г. & \multicolumn{3}{|c|}{2018 г. } & \multicolumn{3}{|c|}{2019 г. } \\
\hline & $\begin{array}{c}\text { Сумма, } \\
\text { тыс. } \\
\text { руб. }\end{array}$ & $\begin{array}{l}\text { Сумма, } \\
\text { тыс. } \\
\text { руб. }\end{array}$ & $\begin{array}{c}\text { Темп } \\
\text { роста к } \\
2017, \%\end{array}$ & $\begin{array}{c}\text { Измен., } \\
\text { тыс. } \\
\text { руб. }\end{array}$ & \begin{tabular}{|c|} 
Сумма, \\
тыс. \\
руб.
\end{tabular} & $\begin{array}{c}\text { Темп } \\
\text { роста к } \\
2018, \%\end{array}$ & $\begin{array}{l}\text { Измен., } \\
\text { тыс. руб. }\end{array}$ \\
\hline $\begin{array}{l}\text { Доходы, } \\
\text { в том числе }\end{array}$ & 131417,3 & 136243,6 & 103,67 & 4826,3 & 130348,2 & 95,67 & $-5895,4$ \\
\hline $\begin{array}{l}\text { Доход от оказания } \\
\text { услуг (работ) }\end{array}$ & 125419,5 & 133231,2 & 106,23 & 7811,7 & 128974,9 & 96,81 & $-4256,3$ \\
\hline $\begin{array}{l}\text { Расходы, } \\
\text { в том числе }\end{array}$ & 139657,0 & 139321,5 & 99,76 & $-335,5$ & 133059,2 & 95,51 & $-6262,3$ \\
\hline $\begin{array}{l}\text { Расход от оказа- } \\
\text { ния услуг (работ) }\end{array}$ & 137851,7 & 136454,4 & 98,99 & $-1397,3$ & 129221,9 & 94,70 & $-7232,5$ \\
\hline $\begin{array}{l}\text { Чистый операци- } \\
\text { онный результат }\end{array}$ & $-8242,7$ & $-3077,90$ & 37,34 & 5164,8 & $-2711,0$ & 88,08 & 366,9 \\
\hline
\end{tabular}


Из данных табл. 1 следует, что доходы и расходы в целом имеют тенденцию снижения. Несмотря на рост доходов в 2018 г. (увеличились на 3,67\% или 4826,3 тыс.руб. и составили 136243,6 тыс. руб., в 2019 г. они сократились к уровню 2018 г. на 4,33\% или 5895,4 тыс. руб. до 130348,2 тыс.руб.

Доход от оказания услуг (работ) в целом имеет тенденцию роста, что оценивается положительно. В 2018 г. он возрос на $6,23 \%$ или 7811,7 тыс. руб. и составил 1332131,2 тыс. руб., в 2019 г. их прирост к 2017 г. составил 2,83\% или 3555,4 тыс. руб. до 128974,9 тыс. руб.

Одновременно наблюдается устойчивая тенденция снижения расходов с 139657 тыс.руб. до 133059,2 тыс. руб. Так, в 2018 г. они сократились на 0,24\% или 335,5 тыс.руб. В 2019 г. наблюдается сокращение совокупных расходов на 4,49\% или 6262,3 тыс.руб.

Положительно следует оценить снижение расходов от оказания услуг (работ). Так, в 2018 г. они сократились на 1,01\% или 1397,3 тыс. руб. до 136454,4 тыс.руб. В 2019 г. наблюдается сокращение расходов от оказания услуг на 5,3\% или 7232,5 тыс.руб. до 129221,9 тыс.руб.

Отрицательно следует оценить превышение доходов над расходами в 2017-2019 гг. Как следствие, чистый операционный результат имеет отрицательное значение. В 2017 г. он составил 8242,7 тыс.руб., в 2018 г. он возрастает до 3077,9 тыс.руб., несмотря на отрицательное значение. По итогам 2019 г. отрицательный чистый операционный результат деятельности учреждения составил 2711 тыс.руб.

Динамика доходов и расходов от оказания платных услуг (работ) ЛПУ за 2017-2019 гг. представлена на рис. 1.

Из рис. видно, что в 2019 г., по сравнению с 2017 г., достигается увеличение темпов роста доходов от оказания платных услуг (работ) (возросли на 2,83\%) на фоне снижения темпов роста расходов от оказания платных услуг (работ) (сократились на 6,26\%).

Отрицательно следует оценить, превышение расходов над доходами от оказания услуг в 2017-2019 г. на 12432,2 тыс.руб., 3223,2 тыс.руб. и 247 тыс.руб. соответственно. Вместе с тем, снижение превышения расходов над доходами от услуг следует оценить положительно; 


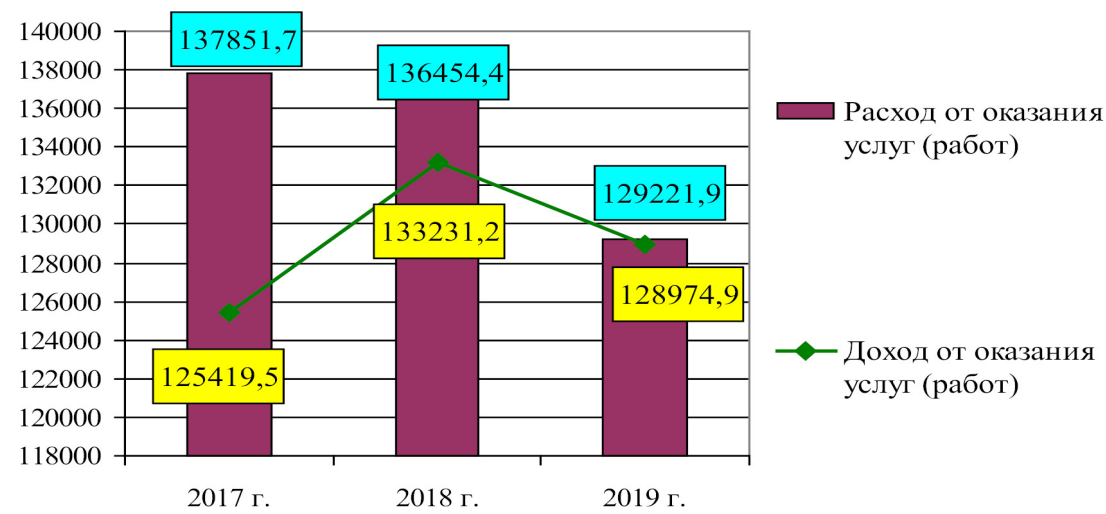

Рис. 1. Динамика доходов и расходов от оказания платных услуг (работ) ГАУЗ «Городская поликлиника №3» за 2017-2019 гг.

2. Анализ и контроль фактического выполнения плановых показателей финансово-хозяйственной деятельности учреждения.

Динамика выполнения плановых показателей ЛПУ за 20172019 гг. представлена в табл. 2.

Таблицуа 2.

Плановые и фактические показатели финансово-хозяйственной деятельности ГАУЗ «Городская поликлиника №3» за 2017-2019 гг., тыс.руб.

\begin{tabular}{|c|c|c|c|c|c|c|}
\hline \multirow{2}{*}{ Показатели } & \multicolumn{2}{|c|}{2017 г. } & \multicolumn{2}{|c|}{2018 г. } & \multicolumn{2}{|c|}{2019 г. } \\
\hline & план & факт & план & факт & план & факт \\
\hline Доходы всего & 116960,5 & 131417,3 & 117675,2 & 136243,6 & 119857,7 & 130348,2 \\
\hline $\mathrm{OMC}$ & 115496,3 & 129953,1 & 117675,2 & 136243,6 & 118657,7 & 129148,2 \\
\hline $\begin{array}{l}\text { Средства бюджета, } \\
\text { переданные в ОМС }\end{array}$ & 1464,2 & 1464,2 & & & 1200,0 & 1200,0 \\
\hline Расходы всего & 116960,5 & 139657,0 & 117675,2 & 139321,5 & 119857,7 & 133059,2 \\
\hline Результат исполнения & & $-8242,7$ & & $-3077,90$ & & $-2711,0$ \\
\hline $\begin{array}{l}\text { Источники финанси- } \\
\text { рования дефицита }\end{array}$ & & 8242,7 & & 3077,90 & & 2711,0 \\
\hline $\begin{array}{l}\text { Чистый доход от ока- } \\
\text { зания платных услуг } \\
\text { (работ) }\end{array}$ & & 8242,7 & & 3077,90 & & 2711,0 \\
\hline $\begin{array}{l}\text { Увеличение остатков } \\
\text { средств }\end{array}$ & & $-133318,3$ & & $-135499,4$ & & $-131046,8$ \\
\hline $\begin{array}{l}\text { Уменьшение остатков } \\
\text { средств }\end{array}$ & & 141561,0 & & 138577,3 & & 133757,8 \\
\hline
\end{tabular}


Как видно из табл. 2, фактическое финансирование в 20172019 гг. ниже утвержденных плановых назначений. Вместе с тем, в результате превышения фактических расходов над доходами, наблюдается снижение дефицита финансирования в размерах 8242,7 тыс.руб., 3077,9 тыс.руб. и 2711 тыс.руб. соответственно. Следует отметить, что в 2018 г. плановое финансирование ГАУЗ «Городская поликлиника №3» осуществлялось на 100\% из бюджета ОМС. Финансирование дефицита учреждения осуществляется за счет чистого дохода от оказания платных услуг (работ).

На основании табл. 3, проведем оценку выполнения плановых показателей финансовой деятельности ЛПУ за 2017-2019 гг.

Таблицуа 3.

Фактическое выполнение плановых показателей по финансовой деятельности ГАУЗ «Городская поликлиника №3» за 2017-2019 гг., \%

\begin{tabular}{|l|r|r|r|}
\hline \multirow{2}{*}{\multicolumn{1}{|c|}{ Показатели }} & \multicolumn{3}{|c|}{ Выполнение плана } \\
\cline { 2 - 4 } & \multicolumn{1}{|c|}{2017 г. } & \multicolumn{1}{c|}{2018 г. } & \multicolumn{1}{c|}{2019 г. } \\
\hline Доходы всего & 112,36 & 115,78 & 108,75 \\
\hline Расходы всего, в том числе & 119,41 & 118,40 & 111,01 \\
\hline ОМС & 112,52 & 115,78 & 108,84 \\
\hline Средства бюджета, переданные в ОМС & 100,00 & - & 100,00 \\
\hline
\end{tabular}

Из табл. 2-3 видно, что плановые показатели доходам и расходам за 2017-2019 гг. в целом не выполняются.

По доходам наблюдается превышение фактических доходов по сравнению с планом. В 2017 г. превышение составило 112,36\% утвержденных сметой плановых назначений, в 2018 г. - 115,78\%, в 2019 г. $-108,75 \%$.

Увеличение фактических показателей компенсируется увеличением финансирования из ОМС и за счет оказания платных услуг по основной деятельности. Так, в 2017 г. за счет увеличения ОМС (возросли на 12,52\%) покрыто 14456 тыс.руб. и 8242,7 тыс.руб. за счет платных услуг. В 2018 г. - 18568,4 тыс.руб. и 3077 тыс.руб., по итогам 2019 г. - дополнительно из ОМС поступило 10490,5 тыс.руб. (возросли на 8,84\%) и 2711 тыс.руб. за счет платных услуг. 
Исполнение фактических расходов по сравнению с утвержденными плановыми назначениями превышают фактические доходы и составляют $119,41 \%, 118,4 \%$ и $111,01 \%$ соответственно. Данная динамика связана преимущественно с ростом расходов за коммунальные услуги и прочих расходов.

Итак, плановые сметы расходов имеют лишь частичное финансовое обеспечение и размер ассигнований на содержание ГАУЗ «Городская поликлиника №3» зависит от состояния местного бюджета и средств ОМС.

В настоящее время одной из актуальных проблем государственных (муниципальных) учреждений является недостаточное бюджетное финансирование. Недостаток денежных средств не позволяет осуществлять полноценное восстановление основных средств, а тем более развитие учреждения. Все это подтверждает невозможность бюджетного учреждения оказывать достаточное количество бесплатных услуг.

В 2019 г. расходы ГАУЗ «Городская поликлиника №3» составили 130348,2 тыс. руб. Структура источников финансирования учреждения за 2019 г. представлена на рис. 2.

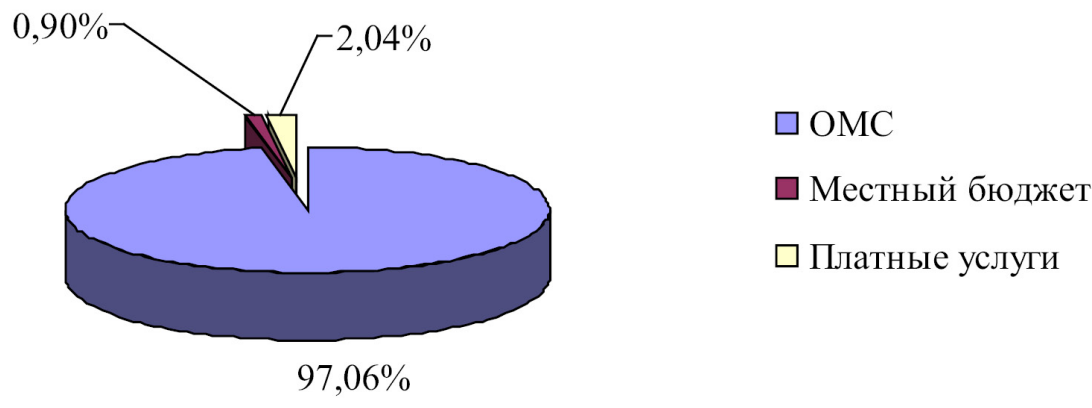

Рис. 2. Структура источников финансирования ГАУЗ «Городская поликлиника №3» за 2019 г., \%

Как видно из рис. 2, наибольшую часть доходов больницы в 2019 г. составляли средства обязательного медицинского страхования $-97,06 \%$. Это объясняется реализацией проекта по переходу на 
одноканальное финансирование здравоохранения в РТ через систему обязательного медицинского страхования (ОМС), призванного обеспечить финансирование всех статей расходов и видов оказываемой медицинской помощи за счет средств ОМС. Для этого постепенно передаются на финансирование за счет средств ОМС те виды помощи, которые ранее финансировались за счет средств местного бюджета.

За счет бюджета финансируются лишь $0,9 \%$ расходов поликлиники, в 2019 г. эти расходы на 100\% связанны с оплатой коммунальных услуг.

На втором месте средства, полученные от платной деятельности поликлиники, они составляют 2,04\%. Все платные медицинские услуги, оказываемые ГАУЗ «Городская поликлиника №3», можно разделить на 4 укрупненных групп в зависимости от направлений оказания медицинской помощи и видов затрат больницы:

- амбулаторно-поликлиническая помощь (в том числе общие лечебные манипуляции, манипуляции сестринского ухода, лечебные манипуляции физиотерапевтического отделения и др.);

- исследования (в том числе общие диагностические исследования отделений функциональной, ультразвуковой диагностики и др.);

- операции (аборты, мини аборты);

- стационар.

Именно по этим группам услуг необходимо осуществлять долгосрочное и краткосрочное финансовое планирование и финансовый менеджмент в ГАУЗ «Городская поликлиника №3» в целом.

Итак, анализ и оценка управления финансами ГАУЗ «Городская поликлиника №3» за 2017-2019 гг. позволил выявить следующие проблемы:

1. Доля расчетов по доходам снижается с 0,41\% в 2017 г. до $0,12 \%$ в 2019 г. Такая динамика связана со снижением как расчетов по доходам от оказания платных услуг, так и расчетов с плательщиками по доходам от собственности (получены от аренды помещений организации);

2. Расходы от оказания услуг в 2017-2019 г. превышают доходы на 12432,2 тыс.руб., 3223,2 тыс.руб. и 247 тыс.руб. соответственно;

3. Плановые сметы расходов имеют лишь частичное финансовое обеспечение и размер ассигнований на содержание ГАУЗ «Городская поли- 
клиника №3» зависит от состояния местного бюджета и средств ОМС;

4. Фактическое финансирование в 2017-2019 гг. выше утвержденных плановых назначений. Плановые показатели доходам и расходам за 2017-2019 гг. в целом не выполняются. По доходам выполнено в 2017 г. 112,36\%, в 2018 г. - 115,78\%, в 2019 г. - 108,75\%. Это связано с дополнительным финансированием запланированных средств из ОМС. Исполнение фактических расходов по сравнению с утвержденными превышают фактические доходы и составляют 119,41\%, $118,4 \%$ и $111,01 \%$ соответственно. Это связано преимущественно с увеличением коммунальных платежей и прочих расходов учреждения.

Следует отметить, широкое распространение в России начинает получать практика зарубежных компаний, предоставляющих своим сотрудникам в составе социального пакета полисы добровольного медицинского страхования. Безусловно, страховые компании, предоставляя услуги ДМС, сотрудничают с различными государственными и частными медицинскими учреждениями, при этом ГАУЗ «Городская поликлиника №3» имеет серьезные конкурентные преимущества на рынке медицинских услуг, особенно в секторе исследований и операций.

Одним из направлений по внедрению маркетинговой политики в ГАУЗ «Городская поликлиника №3», является увеличение дохода на платные услуги через стимулирование спроса на них и активное сотрудничество со страховыми компаниями, осуществляющими добровольное медицинское страхование. Для оценки эффективности предлагаемого проекта, был использован метод матричного сценарного моделирования с учетом негативного, позитивного и средневзвешенного сценариев. Достоинством модели применяемой модели как метода оценки эффективности инвестиционных проектов является то, что она позволяет, варьируя двумя основными переменными факторами (скидкой и ожидаемым приростом спроса на услуги), определять эффективность реализации проектов как по отдельным группам услуг, так и по коммерческой деятельности поликлиники в целом.

Планирование реализации проекта осуществлялось в помесячном разрезе на 2020 г., что позволило учесть сезонность спроса на 
некоторые виды услуг. Предположено, что условия сотрудничества ГАУЗ «Городская поликлиника №3» и страховых компаний предусматривают 15\% скидку на амбулаторно-поликлиническую помощь, $13 \%$ - на стационар, 7\% - на исследования, на операции.

Итак, средневзвешенный годовой чистый денежный поток по рассматриваемому проекту равен 260,5 тыс.руб. Чистый денежный поток по проекту варьируется от 7,65 тыс. руб. в июле для негативного сценария до 41,52 тыс. руб. в ноябре для оптимистичного сценария.

При реализации рассмотренного проекта с заданными переменными факторами (величиной скидки для добровольного медицинского страхования и ожидаемым приростом спроса на услуги) ГАУЗ «Городская поликлиника №3» в прогнозе на 2020 г., не осуществляя фактически никаких прямых затрат, за счет сотрудничества со страховыми компаниями и использования своих конкурентных преимуществ по сравнению с другими медицинскими учреждениями (наличие современного оборудования и высококвалифицированных специалистов), как государственными, так и частными, может получить среднегодовой прирост чистой прибыли от платных медицинских услуг по сравнению с 2016 г. (2711 тыс. руб.) на 9,61\%.

Следует учитывать, что в расчетах использовались достаточно невысокие показатели среднемесячного и среднегодового прироста спроса на платные услуги (около 9\% для средневзвешенного сценария), фактический же прирост спроса при долгосрочном сотрудничестве с крупными страховыми компаниями по добровольному медицинскому страхованию может быть гораздо больше. Это сотрудничество может стать значительным дополнительным источником прибыли поликлиники от оказания платных медицинских услуг за счет роста спроса на них при предоставлении скидок по различным группам услуг.

Таким образом, увеличение притока денежных средств в исследуемой организации, как и в аналогичных местных структурах системы здравоохранения РТ, возможно только за счет возрастания спроса на платные медицинские услуги больницы, при относительно постоянном, корректируемом на инфляцию, уровне цен. Одним из способов стимулирования роста спроса на платные медицинские 
услуги является сотрудничество поликлиники со страховыми компаниями, осуществляющими добровольное медицинское страхование.

\section{Сиисок литературы}

1. Баранов А.А., Лапин Ю.Е. Формирование государственной политики в области здравоохранения в Российской Федерации: проблемы и решения // Вопросы современной педиатрии. 2016. № 6. С. 5-7. URL: https:/cyberleninka.ru/article/n/formirovanie-gosudarstven№y-politiki-voblasti-zdravoohraneniya-v-rossiyskoy-federatsii-problemy-i-resheniya

2. Батиевская В.Б., Шабашев В.А. Трансформация подходов к государственному регулированию российского здравоохранения // Вестник Омского государственного университета. Сер. Экономика. 2013. № 2. С. 66-72. URL: https://cyberleninka.ru/article/n/ transformatsiya-podhodov-k-gosudarstven№mu-regulirovaniyurossiyskogo-zdravoohraneniya

3. Волкова Н.С. Модернизация здравоохранения и совершенствование статуса его учреждений // Журнал российского права. 2015. № 4. C. 54-61. URL: https://cyberleninka.ru/article/n/modernizatsiyazdravoohraneniya-i-sovershenstvovanie-statusa-ego-uchrezhdeniy

4. Денисова И.П., Рукина С.Н. Оценка эффективности и результативности целевых программ при переходе к «программному бюджету» // Фундаментальные исследования. 2013. № 8-2. С. 399-404.

5. Дягилева Н.В. Эффективность государственных расходов на услуги здравоохранения // Известия Оренбургского государственного аграрного университета. 2014. № 6. C. 205-208. URL: https:// cyberleninka.ru/article/n/effektiv№st-gosudarstvennyh-rashodov-nauslugi-zdravoohraneniya

6. Зинурова Г.Х., Сафаргалиев Э.Р. Методы и приемы управления затратами в здравоохранении // International Research Journal. 2020. №5 (95). C.35-38. DOI: https://doi.org/10.23670/IRJ.2020.95.5.038

7. Ваславская И.Ю., Зинурова Г.Х., Кашипова Г.М. Изучение и оценка выявленных проблем при реализации государственных программ по поддержке здравоохранения // Экономика: вчера, сегодня, завтра. 2020. №1A. Том 10. DOI: 10.34670/AR.2020.91.1.066 
8. Калашников К.Н. Ресурсное обеспечение российского здравоохранения: проблемы территориальной дифференциации // Экономические и социальные перемены: факты, тенденции, прогноз. 2015. № 1. С. 72-87. URL: https://cyberleninka.ru/article/n/resurs№e-obespechenierossiyskogo-zdravoohraneniya-problemy-territorial№y-differentsiatsii

9. Щепин О.П. Региональные аспекты развития здравоохранения // Проблемы социальной гигиены, здравоохранения и истории медицины. 2014. № 5. С. 3-7. URL: https://cyberleninka.ru/article/n/ regionalnye-aspekty-razvitiya-zdravoohraneniya

10. Попова Г.В. Методические основы оценки и оптимизации ресурсного обеспечения учреждений здравоохранения на основе модели бюджетирования // ФЭС: Финансы. Экономика. Стратегия. 2010. № 3. С. 7-13.

11. Pulay G., Máté J., Németh I., Zelei A. Budgetary Risks of Monetary Policy with Special Regard to the Debt Rule // Public Finance Quarterly. 2013. Vol. 58. № 1. P. 11-34.

12. Фёдорова Е.А. Разработка пороговых критических значений макроэкономических показателей для предсказания кризисных ситуаций // Е.А. Фёдорова, Ф.Ю. Фёдоров, М.П. Лазарев // Финансы и кредит. 2016. №22. C. 17-26.

13. Schilperoort W., Wierts P. Illuminating Budgetary Risks: the Role of Stress Testing // OECD Journal on Budgeting. 2012. Vol. 12. №o 3. P. 1-18.

14. Шубина Т.В. Оценка эффективности деятельности бюджетной организации в процессе аудиторской проверки / Т.В. Шубина // Аудиторские ведомости. 2017. №1. С. 38-50.

15. Яшина Н.И. Совершенствование управления финансами государственных учреждений здравоохранения / Н.И. Яшина, К.С. Яшин, Е.А. Хансуварова // Экономический анализ. 2016. № 5. С. 85-98.

\section{References}

1. Baranov A.A., Lapin Yu.E. Voprosy sovremennoy pediatrii [Questions of modern pediatrics]. 2016. No. 6. P. 5-7. https://cyberleninka.ru/article/n/formirovanie-gosudarstven№y-politiki-v-oblasti-zdravoohraneniya-v-rossiyskoy-federatsii-problemy-i-resheniya

2. Batievskaya V.B., Shabashev V.A. Vestnik Omskogo gosudarstvennogo universiteta. Ser. Ekonomika [Bulletin of Omsk State University. 
Economy]. 2013. No. 2. P. 66-72. https://cyberleninka.ru/article/n/transformatsiya-podhodov-k-gosudarstven№mu-regulirovaniyu-rossiyskogo-zdravoohraneniya

3. Volkova N.S. Zhurnal rossiyskogo prava [Journal of Russian law]. 2015. No. 4. P. 54-61. https://cyberleninka.ru/article/n/modernizatsiya-zdravoohraneniya-i-sovershenstvovanie-statusa-ego-uchrezhdeniy

4. Denisova I.P., Rukina S.N. Fundamental'nye issledovaniya [Fundamental research]. 2013. No. 8-2. P. 399-404.

5. Diaghileva N.V. Izvestiya Orenburgskogo gosudarstvennogo agrarnogo universiteta [News of the Orenburg State Agrarian University]. 2014. No. 6. P. 205-208. https://cyberleninka.ru/article/n/effektivoost-gosudarstvennyh-rashodov-na-uslugi-zdravoohraneniya

6. Zinurova G.Kh., Safargaliev E.R. International Research Journal. 2020. No. 5 (95). P. 35-38. DOI: https://doi.org/10.23670/IRJ.2020.95.5.038

7. Vaslavskaya I.Yu., Zinurova G.Kh., Kashipova G.M. Ekonomika: vchera, segodnya, zavtra [Economy: yesterday, today, tomorrow]. 2020. No. 1A. Vol. 10. DOI: 10.34670/AR.2020.91.1.066

8. Kalashnikov K.N. Ekonomicheskie i sotsial'nye peremeny: fakty, tendentsii, prognoz [Economic and social changes: facts, trends, forecast]. 2015. No. 1. P. 72-87. https://cyberleninka.ru/article/n/resurs№e-obespechenie-rossiyskogo-zdravoohraneniya-problemy-territorial№y-differentsiatsii

9. Shchepin O.P. Problemy sotsial'noy gigieny, zdravookhraneniya i istorii meditsiny [Problems of social hygiene, health care and history of medicine]. 2014. No. 5. P. 3-7. URL: https://cyberleninka.ru/article/n/ regionalnye-aspekty-razvitiya-zdravoohraneniya

10. Popova G.V. FES: Finansy. Ekonomika. Strategiya [FES: Finance. Economy. Strategy]. 2010. No. 3. P. 7-13.

11. Pulay G., Máté J., Németh I., Zelei A. Budgetary Risks of Monetary Policy with Special Regard to the Debt Rule. Public Finance Quarterly. 2013. Vol. 58. No. 1. P. 11-34.

12. Fedorova E.A, Fedorov F.Yu., Lazarev M.P. Finansy $i$ kredit [Finance and Credit]. 2016. No. 22. P. 17-26.

13. Schilperoort W., Wierts P. Illuminating Budgetary Risks: the Role of Stress Testing. OECD Journal on Budgeting. 2012. Vol. 12. No 3. P. 1-18. 
14. Shubina T.V. Auditorskie vedomosti [Audit statements]. 2017. No. 1. P. 38-50. 15. Yashina N.I., Yashin K.S., Khansuvarova E.A. Ekonomicheskiy analiz [Economic analysis]. 2016. No. 5. P. 85-98.

\section{ДАННЫЕ ОБ АВТОРАХ}

Зинурова Гузель Халитовна, старший преподаватель кафедры «Менеджмент и экономико-математических дисциплин» УВО «Университет управления «ТИСБИ» ул. Комсомольская Набережная, 6, г. Набережные Челны, Республика Татарстан, 423803, Российская Федерация gzinurova80@mail.ru

Сафаргалиев Эрнст Раисович, доцент кафедры «Производственный менеджмент», кандидат педагогических наук Казанский (Приволжский) Федеральный Университет, Набережночелнинский Институт

проспект Мира, 68/19 (1/18), г. Набережные Челны, Республика Татарстан, 423812, Российская Федерация 927242@mail.ru

\section{DATA ABOUT THE AUTHORS}

Zinurova Guzel Khalitovna, Senior Teacher, Management and Economic and Mathematical Subjects Department

Universitet Upravleniya TISBI

6, Komsomolskaya Naberezhnaya, Naberezhnye Chelny, Republic of Tatarstan, 423803, Russian Federation gzinurova80@mail.ru

Safargaliev Ernst Raisovich, Senior Lecturer, Industrial Management, Cand.Sc.Education Kazansky (Privolzhsky) Federalny Universitet, Naberezhniochelninsky Institut 68/19 (1/18), Prospekt Mira, Naberezhnye Chelny, Republic of Tatarstan, 423812, Russian Federation 927242@mail.ru 